\title{
RESEARCH
}

\section{Multifaceted intervention to improve diagnosis and treatment of osteoporosis in patients with recent wrist fracture: a randomized controlled trial}

\author{
Sumit R. Majumdar MD MPH, Jeffrey A. Johnson PhD, Finlay A. McAlister MD MSc, \\ Debbie Bellerose BScN, Anthony S. Russell MD, David A. Hanley MD, Don W. Morrish MD PhD, \\ Walter P. Maksymowych MD, Brian H. Rowe MD MSc
}

\section{ABSTRACT}

Background: Older patients who experience a fragility fracture are at high risk of future fractures but are rarely tested or treated for osteoporosis. We developed a multifaceted intervention directed at older patients with wrist fractures (in the form of telephone-based education) and their physicians (in the form of guidelines endorsed by opinion leaders, supported by reminders) to improve the quality of osteoporosis care.

Methods: In a randomized controlled trial with blinded ascertainment of outcomes, we compared our intervention with usual care (provision of printed educational materials to patients). Eligible patients were those older than 50 years of age who had experienced a wrist fracture and were seen in emergency departments and fracture clinics; we excluded those who were already being treated for osteoporosis. The primary outcome was bisphosphonate treatment within 6 months after the fracture. Secondary outcomes included bone mineral density testing, "appropriate care" (consisting of bone mineral density testing with treatment if bone mass was low) and quality of life.

Results: We screened 795 patients for eligibility and randomly assigned 272 to the intervention (137 patients) or control (135 patients) group. The median age was 6o years; 210 $(77 \%)$ of the subjects were women, and 130 (48\%) reported a previous fracture as an adult. Six months after the fracture, 30 (22\%) of the intervention patients, as compared with $10(7 \%)$ of the control patients, were receiving bisphosphonate therapy for osteoporosis (adjusted relative risk [RR] 2.6, 95\% confidence interval $[\mathrm{Cl}] \mathbf{1 . 3}-5.1, p=0.008$ ). Intervention patients were more likely than control patients to undergo bone mineral density testing (71/137 [52\%] v. 24/135 [18\%]; adjusted RR 2.8, 95\% Cl 1.9-4.2, $p<0.001$ ) and to receive appropriate care (52/137 [38\%] v. 15/135 [11\%]; adjusted RR 3.1, $95 \% \mathrm{Cl} 1.8-5.3, p<0.001)$. There were no differences between the groups in other outcomes. One patient died, and 4 others experienced recurrent fracture.

Interpretation: A multifaceted intervention directed at highrisk patients and their physicians substantially increased rates of testing and treatment for osteoporosis. Nevertheless, more than half of the patients in the intervention group were not receiving appropriate care 6 months after their fracture, which suggests that additional strategies should be explored. (ClinicalTrials.gov trial register no. NCTo0152321.)

Une version française de ce résumé est disponible à l'adresse www.cmaj.ca/cgi/content/full/I78/5/569/DCI

CMAJ 2008;178(5):569-575

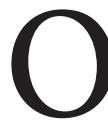
steoporosis is a common, chronic and costly condition affecting at least $25 \%$ of women and $\mathrm{r} 2 \%$ of men over 50 years of age. ${ }^{1-3}$ Without better prevention strategies, the incidence of and costs related to osteoporotic fractures are expected to increase by 50\% over the next 2 decades. ${ }^{3}$ Case-finding and secondary prevention (e.g., by identifying patients who have experienced a fragility fracture, ensuring that their bone mineral density is tested and offering efficacious osteoporosis treatments to those with low bone mass) constitute the most cost-effective strategy for reducing future fractures. ${ }^{4-6}$

An obvious target group for case-finding consists of older patients who experience a wrist fracture. Wrist fracture is the most common symptomatic fracture related to osteoporosis; its occurrence is a powerful forecaster of future fractures, and these fractures typically occur I0-20 years before the more devastating osteoporosis-related fractures of the spine or the hip. ${ }^{7}$ Unfortunately, although most older patients with wrist fractures have low bone mass and are eligible for treatment, ${ }^{4,7}$ less than about 10\% to $20 \%$ are tested or treated for osteoporosis in the 6 to $\mathrm{I} 2$ months after a wrist fracture..$^{4-9}$

We previously reported a nonrandomized study of an intervention that incorporated patient education, physician reminders and treatment guidelines endorsed by opinion leaders, to improve osteoporosis treatment in patients with wrist

From the Departments of Medicine (Majumdar, McAlister, Bellerose, Russell, Morrish, Maksymowych) and Emergency Medicine (Bellerose, Rowe) and the School of Public Health (Johnson), University of Alberta, Edmonton, Alta.; and the Department of Medicine (Hanley), University of Calgary, Calgary, Alta. 
fractures; in that study, which involved 102 patients, the rate of treatment was $40 \%$ in the intervention group but only 10\% in the group receiving usual care. ${ }^{7}$ Several concerns were raised about the internal and external validity of that small study, so we conducted a randomized controlled trial of the intervention, which is reported here.

\section{Methods}

\section{Setting and subjects}

Capital Health (Edmonton, Alberta) is one of the largest integrated health delivery systems in Canada. There is uniform access to bone mineral density testing across the region, with average wait times of less than I week. We screened and recruited consecutive patients from the 2 largest emergency departments and the 2 largest fracture clinics in the region. Inclusion criteria were age 50 years or older and any distal forearm fracture, regardless of cause. Patients were excluded if they were already receiving treatment for osteoporosis with a bisphosphonate, were unable or unwilling to provide informed consent, had no fixed address, were residing outside the Capital Health region or were residing in a long-term care facility.

\section{Study design and procedures}

In this randomized controlled trial, patients were assigned to either the intervention group or the control group. Allocation was concealed by application of variable block sizes and by use of a secure, centralized, Internet-based, computer-generated randomization system housed within the Epidemiology Coordinating and Research Centre at the University of Alberta in Edmonton. Patients could not be blinded to the fact that they were part of an osteoporosis quality improvement study. However, physicians were not informed that their patients were part of a study, and neither physicians nor patients were aware of the study outcomes. Research nurses collected outcomes data without knowledge of allocation status. Investigators were blinded at all times. The University of Alberta Health Research Ethics Board approved the study.

Patients were approached in the emergency departments or while awaiting appointments in fracture clinics. After providing written informed consent, each study patient received a package that included instructions for cast care, information about the study and an Osteoporosis Canada pamphlet entitled "Osteoporosis: Are You at Risk?" The pamphlet described osteoporosis and its risk factors (highlighting the importance of fractures as a harbinger of future events), diagnosis and treatments; emphasized the importance of follow-up; and provided contact information (in the form of a toll-free number and a website address).

\section{Protocol for control arm}

We mailed another copy of the Osteoporosis Canada pamphlet to all patients in the control group, encouraging them to read it and discuss it with their respective primary care physicians. Physicians of control patients were routinely notified that their patients had been treated for a wrist fracture in the emergency department and were informed of follow-up plans and appointments.

\section{Protocol for intervention arm}

The overall purpose of the intervention was to deliver the following 3 messages to physicians (see Appendix I, available at www.cmaj.ca/cgi/content/full/I78/5/569/DC2/I) and patients (see Appendix 2, available at www.cmaj.ca/cgi/content/full// 178 15/569/DC2/2): (I) this patient is (you are) at high risk of osteoporosis, and a bone mineral density test is needed; (2) without treatment, this patient (you) may be at risk of a future fracture sooner rather than later (i.e., within I year); and (3) bisphosphonate treatment for fracture patients with low bone mass reduces the risk of future fracture by up to $50 \%$. The third of these messages was qualified, however, by stating that bisphosphonates are not appropriate for all patients and that acceptable treatment alternatives include calcitonin (administered intranasally), hormone replacement therapy and raloxifene.

The intervention consisted of 3 components. First, we provided a brief counselling session to intervention patients by telephone, reiterating the same messages as the print materials (Appendix 2). This counselling was provided by an experienced registered nurse (D.B.) who had additional training and expertise in the diagnosis and treatment of osteoporosis. Beyond delivering the 3 study messages, the nurse answered questions and allayed concerns while emphasizing the importance of the patient communicating with his or her physician. The nurse did not interact directly with physicians. Second, we sent (by fax or mail) a patient-specific reminder to each physician of an intervention patient notifying the physician that his or her patient had recently received treatment for a wrist fracture and that the occurrence of the fracture indicated that the patient was at risk for osteoporosis. Third, evidence-based treatment guidelines, representing an actionable summary of available osteoporosis guidelines ${ }^{1,2}$ and having endorsement from 5 local opinion leaders, were sent to these physicians. The local opinion leaders were nominated by regional primary care physicians who had received a previously validated sociometric questionnaire designed to identify educationally influential physician peers in the area of osteoporosis; ${ }^{\mathrm{IO}, \mathrm{II}}$ further details are available upon request from the first author (S.R.M.). The reminder and the treatment guideline were designed to fit together on one printed page, were signed by the opinion leaders and were intended to become part of the patient's medical record (Appendix I). In a formal microcosting study, we found that it took on average Io minutes for an experienced nurse to complete all aspects of the intervention, and the cost was $\$ 9.64$ per patient. ${ }^{12}$

\section{Outcomes}

The primary outcome was starting treatment with a bisphosphonate within 6 months after the fracture. This outcome was determined by patient self-report and was confirmed through dispensing records of local community pharmacies. There was I00\% agreement between self-reporting and dispensing records. The main secondary outcomes were a bone mineral density test and a composite measure of quality that we referred to as guideline-concordant or "appropriate" care. Appropriate care was defined as having undergone a bone mineral density test and receiving bisphosphonate treatment if bone mass was low (i.e., a T score consistent with osteopenia [-I.o to -2.5$]$ or 
osteoporosis [-2.5 or worse] at any skeletal site). ${ }^{1,2,13}$ This composite measure was justified because we anticipated that $30 \%$ of the patients would have normal bone mass and would thus be ineligible for bisphosphonate therapy. ${ }^{1,2}$

\section{Other measures}

At baseline and 6 months, we used validated instruments to collect information regarding health status (with the Medical Outcomes Study Short Form-I $2^{14}$ ), osteoporosis-related quality of life, ${ }^{15}$ wrist-related functional outcomes (with the Upper Limb Disabilities of the Arm, Shoulder, and Hand instrument ${ }^{16,17}$ ), osteoporosis-related knowledge ${ }^{18}$ and satisfaction with care. ${ }^{19}$

\section{Sample size considerations}

With bisphosphonate treatment at 6 months as the primary outcome, control treatment rates of no more than I0\%, a $20 \%$ increase in treatment attributable to the intervention, $\alpha=$ 0.05 and $\beta=0.10$, we calculated a minimum sample size of I 84 patients ( 92 per arm) and then inflated this value by about one-half, to 272 patients.

\section{Data analysis}

The patient was the unit of allocation, analysis and causal inference. This was appropriate as we expected that few, if any, physicians would contribute more than I patient to the study. This assumption proved valid, as the 272 patients in the study were cared for by 266 different primary care physicians. In the main analysis, which was conducted according to the intention-to-treat principle, we compared the proportion of patients achieving the primary outcome in the intervention and control groups. A $\chi^{2}$ test was used to determine statistical significance, and the strength of the association was described with relative risks (RRs) and 95\% confidence intervals (CIs). We prespecified that we would use multivariable logistic regression to adjust the analyses for any postrandomization baseline imbalances that were clinically important (i.e., $>$ I0\% difference between study arms) or statistically significant (i.e., $p<$ o.ro). For continuous patient-reported outcomes, we used a similar analytic framework using $t$ tests and multivariable linear regression. Because these were analyses of secondary outcomes, we examined only patients with complete information, rather than imputing any missing data.

\section{Results}

We screened 795 potentially eligible patients and excluded 523 (Figure I). The main reasons for exclusion were inability or unwillingness to provide informed consent (I8I [35\%]), already being treated for osteoporosis with a bisphosphonate (I37 [26\%]) and residence outside the Capital Health region (I38 [26\%]). Two-thirds of the study patients were enrolled from fracture clinics ( 176 [65\%]) and the rest from emergency departments. We randomly assigned I 37 patients (with I 35 different primary care physicians) to receive the intervention and I 35 patients (I I I physicians) to the control group. By study close-out at 6 months, 23 of the 272 patients (I2 in the intervention group, II in the control group) had withdrawn from the study, had been lost to follow-up or had died (Figure I).

\section{Patient characteristics}

The median age of the 272 study patients was 60 years (interquartile range 55-68 years), 210 (77\%) were female, I30 (48\%) reported a previous fracture after the age of 40 years, all reported a fall as the cause of their injury, and 7I (26\%) reported a fall in the previous year. There were no significant differences between patients enrolled from the fracture clinics and those enrolled from the emergency departments. Intervention and control patients were comparable (Table I), although the intervention patients were somewhat more likely than controls to report acid peptic disease $(p=0.06)$, osteoarthritis $(p=0.03)$ and current smoking $(p=0.06)$, and they reported greater use of calcium $(p=0.04)$ and vitamin D $(p=$ o.o6). All multivariable analyses presented hereafter were adjusted for these 5 variables. There were otherwise no significant differences between intervention and control patients.

\section{Osteoporosis treatment}

Six months after the fracture, 30 (22\%) of the 137 intervention patients, as compared with Io ( $7 \%$ ) of the 135 controls, had achieved the primary study outcome of bisphosphonate treatment for osteoporosis (unadjusted RR 3.0; adjusted RR 2.6, 95\% CI I.3-5.I, $p=0.008$ ) (Figure 2). None of the patients received prescriptions for any treatment other than oral

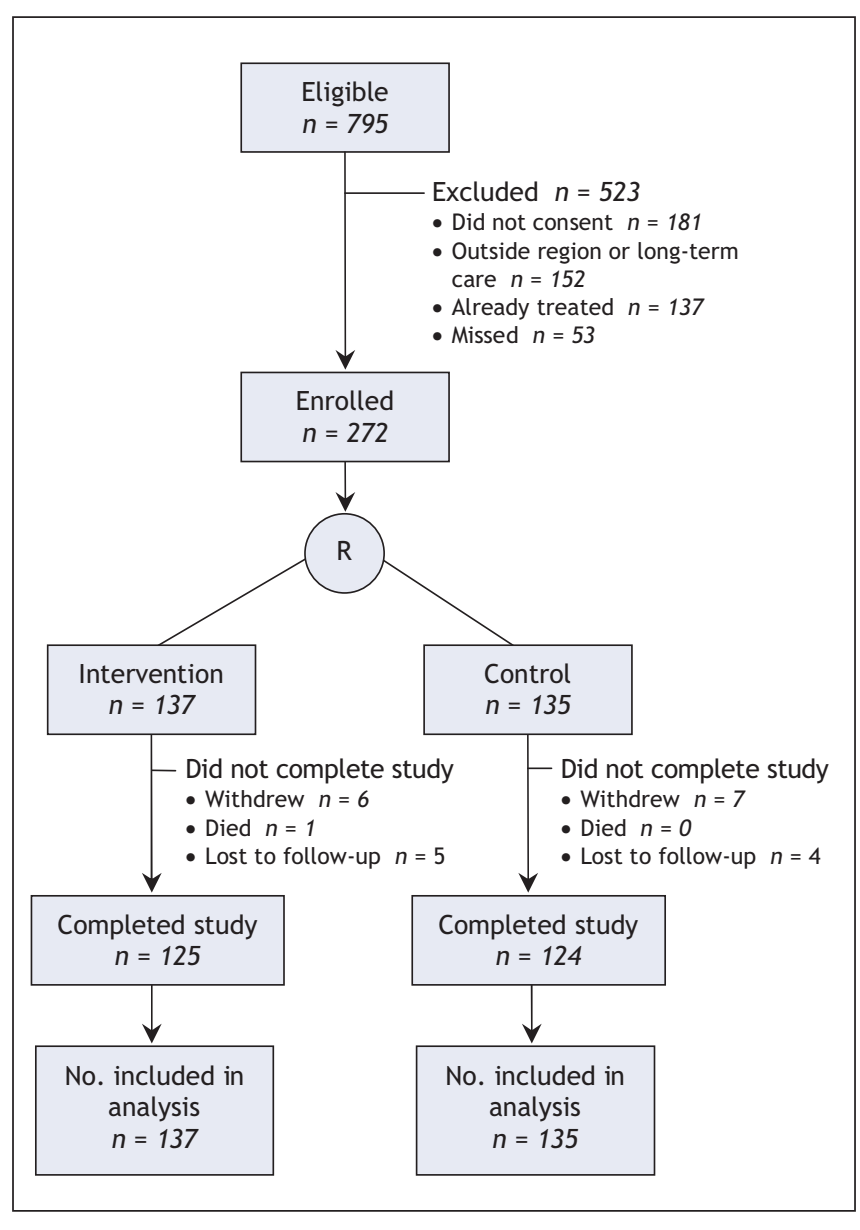

Figure 1: Selection and flow of patients through the study. $\mathrm{R}=$ randomization. 
bisphosphonates (to be taken weekly), and 32 ( $80 \%$ ) of the 40 patients received alendronate. Of the 40 patients who started bisphosphonate therapy, 2 (I in each group) had stopped by 6 months. By the end of the study, 9I (66\%) of the 137 intervention patients and 58 (43\%) of the 135 controls were taking both calcium and vitamin D supplements (unadjusted RR I.6; adjusted RR I.5, 95\% CI I.2-I.9, $p<0.00 I$ ).

\section{Bone mineral density testing}

Within 6 months, 7I (52\%) of the intervention patients, as compared with 24 (I8\%) of the control patients, had undergone a bone mineral density test (unadjusted RR 2.9; adjusted RR 2.8, 95\% CI I.9-4.2, $p<0.00$ I) (Figure 2). Of the 95 pa-

Table 1: Baseline patient characteristics

\begin{tabular}{|c|c|c|}
\hline \multirow[b]{2}{*}{ Characteristic } & \multicolumn{2}{|c|}{ No. (\%) of patients* } \\
\hline & $\begin{array}{c}\text { Intervention } \\
n=137\end{array}$ & $\begin{array}{l}\text { Control } \\
n=135\end{array}$ \\
\hline \multicolumn{3}{|l|}{ Sociodemographic } \\
\hline $\begin{array}{l}\text { Age, yr, median } \\
\text { (interquartile range) }\end{array}$ & $60(55-68)$ & $60(55-69)$ \\
\hline Female & $110(80)$ & $100(74)$ \\
\hline White & $124(91)$ & $122(90)$ \\
\hline $\begin{array}{l}\text { Less than high school } \\
\text { education }\end{array}$ & $40(29)$ & $33(24)$ \\
\hline Retired & $55(40)$ & $46(34)$ \\
\hline Living alone & $44(32)$ & $41(30)$ \\
\hline \multicolumn{3}{|l|}{$\begin{array}{l}\text { Self-reported comorbidity } \\
\text { and health status }\end{array}$} \\
\hline Heart disease & 13 (9) & $17(13)$ \\
\hline High blood pressure & $44(32)$ & $54(40)$ \\
\hline Acid peptic disease & $34(25)$ & $22(16)$ \\
\hline Osteoarthritis & $51(37)$ & $34(25)$ \\
\hline Depression & $29(21)$ & $27(20)$ \\
\hline Excellent or very good health & $77(56)$ & $65(48)$ \\
\hline \multicolumn{3}{|l|}{ Osteoporosis risk factors } \\
\hline Postmenopausal woman & $101(74)$ & $86(64)$ \\
\hline Estrogen therapy in the past & $33(24)$ & $24(18)$ \\
\hline Previous fracture as an adult & $68(50)$ & $62(46)$ \\
\hline Current smoking & $35(26)$ & $22(16)$ \\
\hline No daily milk products & $22(16)$ & $17(13)$ \\
\hline $\begin{array}{l}\text { More than } 2 \text { alcoholic drinks } \\
\text { daily }\end{array}$ & $7 \quad(5)$ & 11 (8) \\
\hline Rheumatoid arthritis & $4 \quad(3)$ & $7 \quad(5)$ \\
\hline Thyroid disease & $18(13)$ & $20(15)$ \\
\hline \multicolumn{3}{|l|}{ Medications and supplements } \\
\hline Calcium supplement & $73(53)$ & $55(41)$ \\
\hline Vitamin D supplement & $64(47)$ & $48(36)$ \\
\hline Any prescription medication & $93(68)$ & $100(74)$ \\
\hline $\begin{array}{l}\text { No. of medications, median } \\
\text { (interquartile range) }\end{array}$ & $2(1-9)$ & $2(1-10)$ \\
\hline
\end{tabular}

*Unless stated otherwise. tients who underwent bone mineral density testing, 27 (28\%) had normal bone mass, 49 (52\%) had osteopenia (T score - I.O to -2.5 ), and I9 (20\%) had osteoporosis (T score -2.5 or worse) at either the hip or the spine.

\section{Appropriate care}

Overall, 52 (38\%) of the intervention patients, as compared with I5 (II\%) of the control patients, received guidelineconcordant (appropriate) osteoporosis care (unadjusted RR 3.4; adjusted RR 3.I, 95\% CI I.8-5.3, $p<0.001$ ) (Figure 2). When results were stratified by sex, men in the intervention group were far less likely than women in that group to receive appropriate care (4/27 [15\%] v. 48/IIO [44\%]). This disparity was magnified among the control patients $(\mathrm{I} / 35[3 \%] \mathrm{v}$. I4/IOO [I4\%]). Of note, all 272 patients had a primary care physician, although only $196(72 \%)$ had visited this physician in the 6 months after the fracture; intervention patients were more likely than control patients to have seen their physician at least once (108 [78\%] v. 88 [65\%], $p=0.02$ ).

\section{Other outcomes}

Overall, by 6 months after randomization, I patient had died and 4 others had experienced recurrent clinical fracture. There were no statistically significant differences between intervention and control patients in patient-reported outcomes such as health status, upper extremity disability, osteoporosis-related quality of life or knowledge, or satisfaction with care (Table 2).

\section{Interpretation}

In this randomized controlled trial with concealed allocation and blinded outcome ascertainment, involving 272 older patients with fracture of the wrist, we demonstrated that a multifaceted intervention led to improved rates of osteoporosis testing and treatment. Compared with an active control group, the intervention group had significantly greater rates of osteoporosis treatment ( $7 \%$ v. $22 \%$ ) and bone mineral density testing ( $18 \%$ v. $52 \%$ ) within 6 months after the fracture. All treated patients received a bisphosphonate, although intranasal calcitonin, hormone replacement therapy, raloxifene, and (currently) parathyroid hormone might be considered reasonable second-line alternatives. Overall, the intervention led to a $27 \%$ absolute increase in the delivery of guideline-concordant ("appropriate") care, which translates into a number needed to treat of 4 patients.

Nevertheless, it should be acknowledged that more than half $(62 \%)$ of the intervention patients were not receiving appropriate osteoporosis care within 6 months after their fracture, either because a bone mineral density test had not been done or because evidence of low bone mass had not been acted upon. This was a particular problem for men, who were about one-third as likely as women to receive appropriate care, irrespective of allocation status. Indeed, the rates of appropriate care for men in the intervention group ( $15 \%$ ) were about the same as for women in the control group ( $14 \%$ ), who in turn were more likely to receive appropriate care than men in the control group (3\%). This disparity is most likely a result of the fact that both male patients ${ }^{20}$ and their physi- 
cians ${ }^{21}$ consider osteoporosis to be a condition that afflicts only elderly women, and our intervention (alone) was insufficient to overcome this profound attitudinal barrier.

Compared with our pilot study of the same intervention, the rates of osteoporosis treatment in the study reported here were lower: $22 \%$ of patients in the current study and $40 \%$ of those in the pilot study were being treated at 6 months after fracture. This difference could be related to bias (i.e., the pilot was stopped early), confounding (i.e., the pilot used nonrandom allocation) or chance. Alternatively, the estimate of effect for osteoporosis treatment in the pilot study (adjusted RR of 3.8) was within the $95 \%$ confidence interval of the effect found in this trial (I.3-5.I), which suggests equivalent benefit. Regardless, it is discouraging to note that, in the 2 years since our original study was published, there was no improvement in osteoporosis treatment rates with usual care after a fracture (10\% in the pilot v. $7 \%$ in the current study) in our own health region. Similarly low rates of osteoporosis treatment after fracture have been reported elsewhere in Canada, in the United States, in Europe and in Australia. ${ }^{4-9}$

To our knowledge, there have been only 3 other randomized controlled trials of interventions to improve the quality of osteoporosis care for outpatients who have experienced a fracture, ${ }^{22-24}$ and 2 of those interventions did not improve treatment. ${ }^{22,23}$ Bliuc and associates ${ }^{22}$ enrolled 159 patients from a single fracture clinic in Australia and randomly assigned them to active control (a letter noting risk factors and recommending follow-up by a primary care physician) or intervention (the same letter plus a free bone mineral density test). The intervention had no effect on osteoporosis treatment after 6 months ( $5 \%$ for intervention v. $7 \%$ for controls, $p>0.4$ ). Solomon and colleagues ${ }^{23}$ enrolled 229 Blue Cross and Blue
Shield beneficiaries from New Jersey who had a previous fracture, randomly assigning them (as a subgroup in a much larger trial) to usual care or intervention (which consisted of academic detailing and reminders to physicians, and printed materials and automated telephone calls to patients). The intervention had no effect on osteoporosis treatment after Io months ( $4 \%$ for intervention v. $\mathrm{I} \%$ for controls, $p=0.07$ ).

The only other study with positive results was reported by Feldstein and colleagues, ${ }^{24}$ who enrolled 3 II older women from a health maintenance organization that was using computerized medical records and electronic prescribing. They randomly assigned them to usual care or interventions (I or 2 patient-specific electronic reminders with locally developed guidelines for physicians, with or without mailing of printed materials to patients). After 6 months, the interventions were associated with greater rates of bone mineral density testing ( $49 \%$ for interventions v. $2 \%$ for controls, $p<0.001$ ) and of osteoporosis treatment ( $28 \%$ v. $5 \%, p<0.00 \mathrm{I}) .{ }^{24}$ Clearly, it is difficult to improve the quality of care for older patients with fractures, and the study by Feldstein and colleagues and our own studies demonstrate that many patients exposed to effective interventions remain untreated.

Like all 3 of the previous randomized trials, ${ }^{22-24}$ we examined process-of-care measures and did not have adequate power to demonstrate reductions in harder outcomes such as recurrent fracture. However, process-of-care measures are more sensitive to changes in quality of care than harder outcomes such as mortality or clinical events and are widely recognized as acceptable and appropriate outcomes for qualityimprovement studies. ${ }^{10,11,25,26}$ Second, we had only 6-month measures of adherence with guidelines for a condition that probably requires at least 5 to Io years of treatment. We have

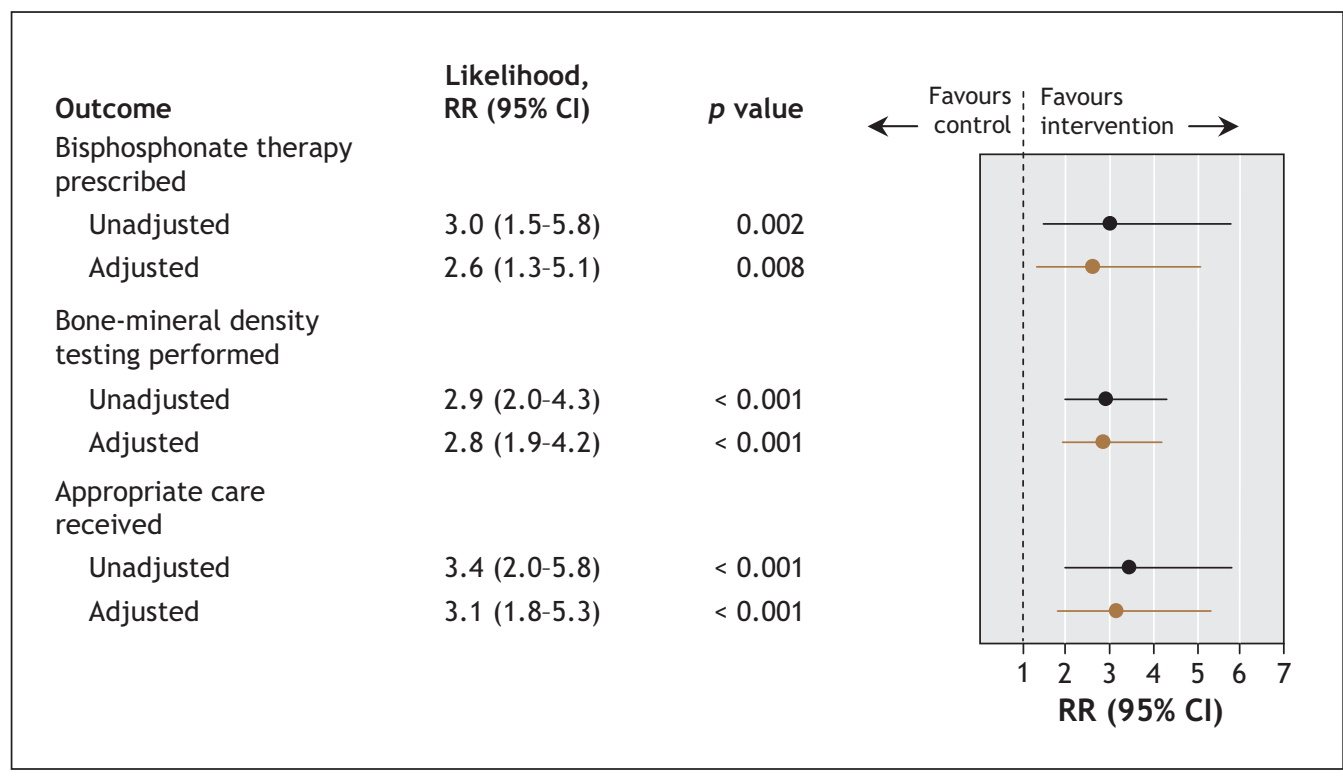

Figure 2: Unadjusted and adjusted likelihood of receiving osteoporosis testing and treatment within 6 months after a wrist fracture among 137 patients randomly assigned to the intervention group (patient education, physician reminder about patient's risk of osteoporosis and physician receipt of evidencebased treatment guidelines) and 135 patients assigned to control group (usual care). RR = relative risk, $\mathrm{Cl}=$ confidence interval. 
Table 2: Patient-reported outcomes 6 months after wrist fracture

\begin{tabular}{|c|c|c|c|}
\hline Patient-reported measure & $\begin{array}{c}\text { Intervention } \\
n=137\end{array}$ & $\begin{array}{c}\text { Controls } \\
n=135\end{array}$ & $\begin{array}{c}p \text { value for } \\
\text { difference (adjusted) }\end{array}$ \\
\hline \multicolumn{4}{|l|}{ Health status* } \\
\hline No. (\%) with SF-12 score & $117(85)$ & $114(84)$ & \\
\hline Mental component score, mean (SD) & 54.9 (7.6) & 53.4 (7.4) & 0.06 \\
\hline Physical component score, mean (SD) & $47.5 \quad(9.2)$ & 46.8 (9.7) & 0.15 \\
\hline \multicolumn{4}{|l|}{ Functional measures } \\
\hline No. (\%) with upper limb function score $†$ & $120(88)$ & $114(84)$ & \\
\hline Disability rating, mean (SD) & $15.5(13.8)$ & $16.7(14.2)$ & 0.23 \\
\hline \multicolumn{4}{|l|}{ Osteoporosis-related variables } \\
\hline $\begin{array}{l}\text { No. }(\%) \text { with score for osteoporosis-related } \\
\text { quality of life } \neq\end{array}$ & $126(92)$ & $122(90)$ & \\
\hline Physical function score, mean (SD) & $75.2(23.6)$ & $71.3(26.1)$ & 0.13 \\
\hline Adaptation score, mean (SD) & $70.5(23.1)$ & $70.9(21.4)$ & 0.59 \\
\hline Fear score, mean (SD) & $74.0(29.5)$ & $71.0(29.9)$ & 0.18 \\
\hline No. (\%) tested for osteoporosis-related knowledge§ & $126(92)$ & $122(90)$ & \\
\hline Osteoporosis test score, mean (SD) & $58.3(30.2)$ & $56.5(30.3)$ & 0.76 \\
\hline \multicolumn{4}{|l|}{ Satisfaction with caref } \\
\hline No. (\%) reporting satisfaction & $134(98)$ & $128(95)$ & \\
\hline Satisfaction score, mean (SD) & $73.5(23.7)$ & $74.3(21.4)$ & 0.92 \\
\hline
\end{tabular}

Note: SF-12 = 12-item Medical Outcomes Study Short Form-12, SD = standard deviation.

${ }^{*}$ As measured by the SF-12. ${ }^{14}$ Physical and mental component scores were standardized to the Alberta population, with a mean score of 50 and SD of 10 . Higher mean scores represent better physical or mental health.

†As measured by the 30 -item Upper Limb Disabilities of the Arm, Shoulder, and Hand instrument. ${ }^{16,17}$ Scored from 0 to 100 , with 0 representing no disability of the upper extremity.

†As measured by the 22-item Osteoporosis-Related Quality of Life instrument. ${ }^{15}$ Three domains (physical function, adaptation and fear) were scored separately, from 0 to 100 , with higher mean scores representing better domain-specific quality of life.

§As measured by the 25-item Facts on Osteoporosis Quiz. ${ }^{18}$ Scored as percentage of correct answers, with higher mean scores representing greater knowledge.

१|As measured by the participant's response (on a 5-point Likert scale) to the statement “The medical care that I have received has been just about perfect." ${ }^{19}$ Responses were converted to percentage scores, with higher mean scores representing greater satisfaction.

planned ongoing follow-up of this study cohort. Third, we can only draw conclusions about the effect of the intervention package as a whole, not about any single component. Although some authorities might consider this a limitation, ${ }^{27}$ an equal number might concur with us in suggesting that our intervention should simply be adopted as part of usual care and could serve as the active comparator control arm for future studies. We suggest that future studies be designed to better understand and explore all barriers to best practice and consider a variety of strategies. Such studies might examine the effects of repeated messaging and reminders to patients and physicians; investigate decision aids to better motivate patients, especially men; consider more clinically useful and directive bone mineral density reports; and, perhaps most important, consider the role of allied health professionals in acting as "fracture managers" to educate patients, facilitate bone mineral density testing and provide prescription treatments when appropriate. ${ }^{28}$

In conclusion, we found that a pragmatic and inexpensive multifaceted intervention directed at patients with fragility fractures and their primary care physicians improved rates of osteoporosis treatment and led to a tripling of the delivery of guideline-concordant (appropriate) care. Still, more than half of the patients in the intervention group did not receive ap- propriate care. We therefore need to find even more effective methods to translate what we already know into what we do everyday - with the caveat that any new interventions should be tested in controlled trials before widespread adoption.

This article has been peer reviewed

Competing interests: None declared for Sumit Majumdar, Jeffrey Johnson, Finlay McAlister, Debbie Bellerose, Anthony Russell, Don Morrish, Walter Maksymowych or Brian Rowe. David Hanley has been a clinical investigator in phase III clinical trials of bisphosphonates manufactured by Proctor \& Gamble, Merck and Novartis; in addition, he has received speaker fees from and has been a paid consultant on advisory boards of these companies.

Contributors: All of the authors participated in the design and conception of the study; the acquisition, analysis and interpretation of the data; critical intellectual revision of the manuscript; and approval of the final version submitted to the journal. Sumit Majumdar also supervised the study, obtained funding, drafted the manuscript and acts as guarantor.

Acknowledgements: Sumit Majumdar, Jeffrey Johnson, Finlay McAlister and Walter Maksymowych receive salary support awards from the Alberta Heritage Foundation for Medical Research; Sumit Majumdar and Finlay McAlister receive salary support awards from the Canadian Institutes of Health Research; Jeffrey Johnson and Brian Rowe hold Canada Research Chairs; and Finley McAlister holds the Aventis/Merck-Frosst Chair in Patient Health Management. The study was supported by peer-reviewed grants from the Canadian Institutes of Health Research. 


\section{REFERENCES}

I. Physicians' guide to prevention and treatment of osteoporosis. Washington (DC) National Osteoporosis Foundation; 2002. Available: www.nof.org/professionals /clinical.htm (accessed 2007 Oct I2).

2. Brown JP, Josse RG; Scientific Advisory Council of the Osteoporosis Society of Canada. 2002 clinical practice guidelines for the diagnosis and management of osteoporosis in Canada. CMAJ 2002;I67(ro Suppl):SI-34.

3. Burge R, Dawson-Hughes B, Solomon DH, et al. Incidence and economic burden of osteoporosis-related fractures in the United States, 2005-2025. J Bone Miner Res 2007;22:465-75.

4. Siris ES, Bilezikian JP, Rubin MR, et al. Pins and plaster aren't enough: a call for the evaluation and treatment of patients with osteoporotic fractures. J Clin Endocrinol Metab 2003;88:3482-6.

5. Elliot-Gibson V, Bogoch ER, Jamal SA, et al. Practice patterns in the diagnosis and treatment of osteoporosis after fragility fracture: a systematic review. Osteoporos Int 2004;15:767-78.

6. Giangregorio L, Papaioannou A, Cranney A, et al. Fragility fractures and the osteoporosis care gap: an international phenomenon. Semin Arthritis Rheum 2006;35:293-305.

7. Majumdar SR, Rowe BH, Folk D, et al. A controlled trial to increase detection and treatment of osteoporosis in older patients with a wrist fracture. Ann Intern Med 2004; I4I:366-73

8. Feldstein A, Elmer PJ, Orwoll E, et al. Bone mineral density measurement and treatment for osteoporosis in older individuals with fractures. Arch Intern Med 2003;163:2165-72.

9. Eisman J, Clapham S, Kehoe L; Australian BoneCare Study. Osteoporosis prevalence and levels of treatment in primary care: the Australian BoneCare Study. J Bone Miner Res 2004;19:1969-75.

Io. Soumerai SB, McLaughlin TJ, Gurwitz JH, et al. Effect of local medical opinion leaders on quality of care for acute myocardial infarction. A randomized controlled trial. JAMA I998;279:1358-63.

II. Majumdar SR, Tsuyuki RT, McAlister FA. Impact of opinion leader-endorsed evidence summaries on the quality of prescribing for patients with cardiovascular disease: a randomized controlled trial. Am Heart J 2007; I53:22-9.

I2. Majumdar SR, Johnson JA, Lier DA, et al. Persistence, reproducibility, and costeffectiveness of an intervention to improve the quality of osteoporosis care after a fracture of the wrist: results of a controlled trial. Osteoporos Int 2007;18:26I-70.

13. Cranney A, Guyatt G, Griffith L, et al. Meta-analyses of therapies for postmenopausal osteoporosis. IX: Summary of meta-analyses of therapies for postmenopausal osteoporosis. Endocr Rev 2002;23:570-8.

I4. Ware J Jr, Kosinski M, Keller SD. A I2-item short form health survey: construction of scales and preliminary test of reliability and validity. Med Care 1996;34:220-33.
15. Lydick E, Zimmerman SI, Yawn B, et al. Development and validation of a discriminative quality of life questionnaire for osteoporosis (the OPTQoL). $J$ Bone Miner Res 1997;12:456-63.

I6. Hudak PL, Amadio PC. Bombardier C, et al. Development of an upper extremity outcome measure: the DASH (disabilities of the arm, shoulder, and hand). Am J Ind Med 1996;29:602-8.

17. Upper limb - disabilities of the arm, shoulder, and hand (DASH), version 2. Rosemont (IL): American Academy of Orthopedic Surgeons; I998. Available: www.aaos.org (accessed 2007 Oct I2).

I8. Ailinger RL, Harper DC, Lasus HA. Bone up on osteoporosis. Development of the Facts on Osteoporosis Quiz. Orthop Nurs 1998;17(5):66-73.

I9. Marshall GN, Hays RD. The patient satisfaction questionnaire short-form (PSQI8). Santa Monica (CA): Rand Corporation; I994.

20. Sedlak CA, Doheny MO, Estok PJ. Osteoporosis in older men: knowledge and health beliefs. Orthop Nurs 2000;19(3):38-42, 44-6.

2I. Jaglal SB, Carrol J, Hawker G, et al. How are family physicians managing osteoporosis? Qualitative study of their experiences and educational needs. Can Fam Physician 2003;49:462-8.

22. Bliuc D, Eisman JA, Center JR. A randomized study of two different informationbased interventions on the management of osteoporosis in minimal and moderate trauma fractures. Osteoporos Int 2006;17:1309-I7.

23. Solomon DH, Polinski JM, Stedman M, et al. Improving care of patients at risk for osteoporosis: a randomized controlled trial. J Gen Intern Med 2007;22:362-7.

24. Feldstein A, Elmer PJ, Smith DH, et al. Electronic medical record reminder improves osteoporosis management after a fracture: a randomized controlled trial. J Am Geriatr Soc 2006;54:450-7.

25. Brook RH, McGlynn EA. Measuring quality of care. N Engl J Med ı996;335:966-8.

26. Higashi T, Shekelle PG, Adams JL, et al. Quality of care is associated with survival in vulnerable older patients. Ann Intern Med 2005;I43:274-8I.

27. Shojania KG, Grimshaw JM. Evidence-based quality improvement: the state of the science. Health Aff (Millwood) 2005;24:138-50.

28. Majumdar SR, Beaupre LA, Harley $\mathrm{CH}$, et al. Use of a case manager to improve osteoporosis treatment after hip fracture: results of a randomized controlled trial. Arch Intern Med 2007;167:2110-5.

Correspondence to: Dr. Sumit R. Majumdar, Associate Professor, Department of Medicine, University of Alberta, $2 E_{3} .07$ Walter Mackenzie Health Sciences Centre, University of Alberta Hospital, 8440-II2th St., Edmonton AB T6G 2B7; fax 780 407-2680; me2.majumdar@ualberta.ca

\section{BOURSE POSTDOCTORALE EN RÉDACTION DU JAMC}

La BOURSE POSTDOCTORALE EN RÉDACTION DU JAMC offre aux médecins en début de formation une occasion intéressante de découvrir les rouages internes d'un journal médical de premier plan. Nous invitons les personnes qui ont terminé leur formation en médecine et leur résidence, ainsi que leur formation en épidémiologie clinique, à présenter une demande. Les boursiers participent à tous les aspects de la production du journal, depuis la prise des décisions sur les manuscrits publiés jusqu'à la sollicitation de commentaires et d'articles d'analyse. Les boursiers doivent aussi beaucoup écrire et nous les encourageons à créer des numéros thématiques, des séries ou d'autres innovations pour le journal.

Ce poste à plein temps d'une durée d'un an est offert dans les bureaux du JAMC à Ottawa. Le salaire est fondé sur la rémunération équivalente de résident ou de fellow en Ontario.

La prochaine série de demandes porte sur la bourse de recherche de 2008 qui commence à l'été 2008. II faut présenter sa demande au plus tard le 25 mars 2008.

Pour obtenir plus de renseignements, veuillez communiquer avec le $D^{r}$ Paul C. Hébert, rédacteur-en-chef, à paul.hebert@cma.ca.

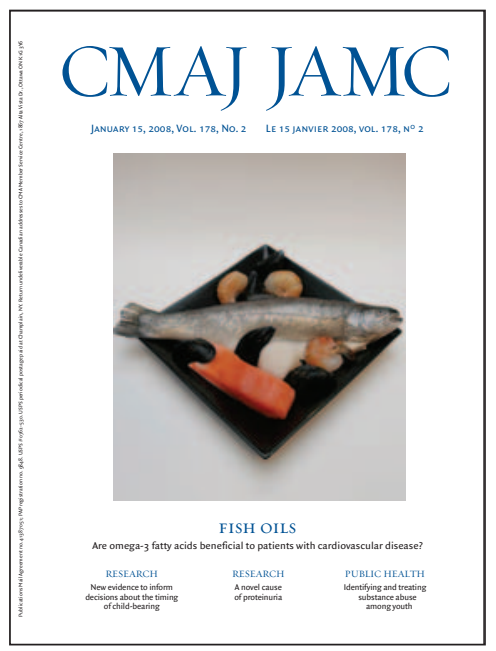

\section{CMAJ·JAMC}

